\title{
What kind of third molars are disease-free in a population aged 30 to 93 years?
}

\author{
Ventä, Irja
}

2019-03

Ventä , I , Vehkalahti , M M \& Suominen , A L 2019 , ' What kind of third molars are disease-free in a population aged 30 to 93 years? ' , Clinical Oral Investigations , vol. 23 , no. 3 , pp. 1015-1022 . https://doi.org/10.1007/s00784-018-2528-5

http://hdl.handle.net/10138/325896

https://doi.org/10.1007/s00784-018-2528-5

unspecified

acceptedVersion

Downloaded from Helda, University of Helsinki institutional repository.

This is an electronic reprint of the original article.

This reprint may differ from the original in pagination and typographic detail.

Please cite the original version. 
Irja Ventä ${ }^{1}$, Miira M. Vehkalahti ${ }^{1}$, Anna L. Suominen ${ }^{2}$

What kind of third molars are disease-free in a population aged 30 to 93 years?

${ }^{1}$ Department of Oral and Maxillofacial Diseases, University of Helsinki, Helsinki, Finland

${ }^{2}$ Institute of Dentistry, University of Eastern Finland, Kuopio, Finland, and Department of Oral and

Maxillofacial Diseases, Kuopio University Hospital, Kuopio, Finland, and Public Health Evaluation and Projection Unit, National Institute for Health and Welfare, Helsinki, Finland

Address for correspondence: Irja Ventä, Department of Oral and Maxillofacial Diseases, Faculty of Medicine, P.O. Box 41, FI-00014 University of Helsinki, Helsinki, Finland. Email: irja.venta@helsinki.fi; Phone: +358 50 4151309, Fax: +358 919127265 .

Acknowledgements: Field surveys were organized by the National Institute for Health and Welfare (THL) in Finland and partly funded by the Finnish Dental Society Apollonia and the Finnish Dental Association. Planmeca Oy placed digital panoramic X-ray apparatus and software at our disposal during the survey. The first author received a grant for this study from the Finnish Association of Women Dentists. 


\begin{abstract}
Objectives: The aim of the study was to characterize third molars that have remained disease-free in a representative sample of the Finnish population aged 30 years and older.

Materials and Methods: Two-staged stratified cluster sampling ( $\mathrm{N}=8028)$ was used, and 6005 subjects participated in a clinical oral examination and panoramic radiography. Disease-free third molars were characterized as follows: no dentinal caries, no filling, periodontal pocket depths of neighboring second molars less than $4 \mathrm{~mm}$, and no radiographic pathological findings. Logistic regression analyses served for assessment of the strength of characteristics of third molars for disease-free status.
\end{abstract}

Results: Of the subjects, 2653 (44\%) had at least one third molar. Of them, the majority (62\%) had only diseased third molars, $16 \%$ had only disease-free ones, and 22\% had both. Participants had in total 5665 third molars; $29 \%$ of them were disease-free. Female gender, higher level of education, and younger age were related to disease-free status $(\mathrm{P}<0.001)$. Disease-free status was more likely for third molars at cervical or apical level than at occlusal level: odds ratio was 10.1 for all teeth, 8.5 for maxillary teeth, and 6.2 for mandibular teeth.

Conclusion: A third molar situated deeper in the bone was more likely to be disease-free than a tooth at occlusal level in the population aged 30 years and older.

Clinical Relevance: Our results suggest that the number of disease-free third molars decreased with increasing age and most dramatically this occurred among teeth at cervical level with the neighboring second molar.

Key words: third molar; pathology; adult population; epidemiology; panoramic radiograph 


\section{Introduction}

One of the reasons for early extraction of third molars is the possibility that a pathological condition may develop later in life [1]. Therefore, a researcher's interest is often focused on third molars at the most common period of extraction, i.e. in adolescence and young adulthood, and little is known of the later course of life of these teeth. However, it would be very important for the clinician to understand what kind of third molars may remain disease-free throughout the human life span. For example, in a case with a challenging position in relation to the mandibular canal, where one must decide whether to leave or extract, predicting whether the tooth will remain symptomless and uneventful for the rest of life would be invaluable.

In reality, most third molars become extracted during one's life time. However, according to populationbased oral health surveys, a few third molars survive to old age. In the Finnish population aged over 65 years, $5 \%$ of dentate subjects have clinically visible third molars [2], and in the US population at the age of 69 years the mean number of clinically visible third molars is 0.81 per person [3]. However, these findings are solely based on clinical examination, not on radiographs.

Studies on disease-free third molars in adult populations are rare. In a longitudinal study among US participants aged 14 to 45 years and carried out at two academic centers, one-third of subjects retain third molars free of periodontal pathology during the 6-year follow-up [4]. These subjects are characterized as being young, well-educated, and with good oral health habits. However, characteristics of the third molars other than probing depths of less than $4 \mathrm{~mm}$ are not reported. In another study of patients at oral and maxillofacial surgery, $11.6 \%$ of subjects with median age of 25 years have all third molars present and also asymptomatic and disease-free [5].

Our recent paper reports on signs of disease in third molars in a representative sample of the Finnish population aged 30 years and over [6]. Clinical or radiographic pathological findings are common, occurring in $61 \%$ of the $30-44$-year-olds and in $94 \%$ of those aged 75 years and older. However, onefourth of all third molars remain without any signs of disease. Therefore, we identified these teeth to determine any common features. The aim of this study is to characterize those third molars that have remained disease-free in the Finnish population aged 30 years and over. 


\section{Materials and Methods}

Study design

Our study was part of the Health 2000 Survey (BRIF8901, Bioresource Research Impact Factor)

organized by the National Institute for Health and Welfare in Finland during 2000 and 2001 [7, 8]. The study design used the two-staged stratified cluster sampling method to select the 8028 participants representing the Finnish population aged 30 years and over [9]. In addition to a general health examination, questionnaires, and health interviews, the survey also included a clinical oral examination and panoramic radiographs.

A total of 6335 subjects participated in the clinical oral examination and 6115 panoramic radiographs were taken (Figure 1). After excluding 110 radiographs due to inadequate quality around the third molar area, the data for 6005 subjects remained. Of subjects' demographic features, the following were included in the analysis: age, gender, level of education (basic, middle, higher), and place of residence (city, town, countryside) [9]. Age was categorized as 30-39, 40-49, 50-59, 60-69, and 70 years or older.

\section{Clinical examination}

The clinical oral examinations were conducted by five dentists with the assistance of a dental nurse. The following measurements from the clinical examination were included in the present study: dentinal caries and restorations of third molars and the depth of periodontal pockets of second molars adjacent to third molars. The pockets were probed from four sites around the tooth (distal angle, buccal mid-point, lingual mid-point, and mesiolingual angle), and the deepest measurement was recorded [2].

Radiographic examination

Participation in the radiographic examination was voluntary and pregnant subjects were excluded. Digital panoramic radiographs were taken with Planmeca 2002 CC Proline (Planmeca, Helsinki, Finland) equipment using 58 to $68 \mathrm{kV}$ and 4 to $10 \mathrm{~mA}$ depending on the size of the subject. Images were examined using the Romexis software version 3.6.0.R (Planmeca, Helsinki, Finland). Measuring tools of the software were utilized for determining the width of follicles when needed. 
The first author examined the panoramic radiographs to assess the status of the third molars. The measurements included the state of impaction [10], dentinal caries and/or restorations, angulation of the tooth, depth in the bone [11], and relationship with mandibular canal (Table 1). The angulation was defined as the angle between the occlusal surface of the third molar and the occlusal plane determined by the highest points of occlusal surfaces of the second molar and the first premolar [12]. The angulation was estimated by visual impression alone.

A disease-free third molar was classified as a tooth with no dentinal caries, no fillings, pocket depths of neighboring second molars of less than $4 \mathrm{~mm}$, and none of the following additional pathological findings: retained root, tumor, pericoronitis (width of follicle 3-5 mm), cyst (width of follicle more than $5 \mathrm{~mm}$ ), supernumerary tooth in the third molar region, periapical radiolucent lesion, overeruption, bone loss (horizontally or vertically extending at least to the middle third of the root), rudimental size of the tooth, resorption of the crown, sclerosis of the bone around the tooth, or mandibular fracture through the third molar. Retained third molar roots were excluded from the analysis because all characteristics (angulation) of them could not be assessed.

When examining the panoramic radiographs, 2879 images (47\%) of radiographs were examined a second time after six weeks before proceeding to the rest of the radiographs. This was done as training for the harmonization of interpretations. After examination of all radiographs, 610 (10\%) randomly selected images were re-examined to determine intra-examiner reliability for measurements. Kappa-values ranged from 0.88 to 0.95 for impaction, from 0.83 to 0.92 for angulation, from 0.83 to 0.94 for depth in the bone, from 0.82 to 0.91 for relationship with mandibular canal, and from 0.88 to 1.0 for additional pathological findings.

\section{Statistical analysis}

The analyses took both the subject and the third molar as an observation unit. Subjects were divided into three groups according to the disease status of third molars: only disease-free, only diseased, and both disease-free and diseased. For the evaluation of differences between various subgroups, we used Chisquared test for frequencies, Fisher's exact test when the expected counts were less than five, and Kruskal-Wallis test for mean values. Spearman's correlations were calculated for the characteristics of third molars before regression analysis. Correlations were high between impaction type and depth in the 
bone of third molars ( $\mathrm{r}=0.95$ for upper jaw and $\mathrm{r}=0.78$ for lower jaw), and therefore, these measurements were not entered together into the regression analysis. We fitted logistic regression models first to all third molars and separately for maxillary and mandibular ones. Goodness of fit of the models was evaluated with Hosmer and Lemeshow test. Odds ratios and their 95\% confidence intervals were also calculated. Analyses were computed with IBM SPSS Statistics software version 24 (IBM Corp., Armonk, NY, USA).

Ethical considerations

The study was carried out with permission from the National Institute for Health and Welfare in Finland. Identity of the participants was not disclosed to the authors. Informed subjects participated in the study on an entirely voluntary basis. Ethical approvals for the clinical and radiographic examinations of subjects in the Health 2000 Survey were obtained from the Ethics Committee of the National Public Health Institute and the Ethics Committee of Epidemiology and National Health in the Hospital District of Helsinki and Uusimaa. A safety license was granted by the Radiation and Nuclear Safety Authority of Finland (No. 4969/L1/00).

\section{Results}

Subject-related findings

In total, $2653(44 \%)$ of the 6005 subjects had at least one third molar (Figure 1). The mean age of these subjects was 47.1 years (SD 11.7; median 46; range 30-93 years). The majority, 1652 (62\%), had only diseased third molars, $434(16 \%)$ had only disease-free ones, and 567 (22\%) had both (Table 2).

Demographic characteristics of the subjects differed according to the disease status of their third molars (Table 2). Among those having only disease-free third molars, females and higher educated subjects dominated; among those having both disease-free and diseased third molars, males and higher educated subjects dominated. Subjects in both of these groups were clearly younger than those having only diseased third molars (Kruskal-Wallis $\chi^{2}=199.58 ; \mathrm{df}=2 ; \mathrm{P}<0.001$ ).

Third molar-based findings 
From the total of 5665 third molars, 1669 (29\%) were disease-free. The majority, 870 (52\%), of diseasefree third molars occurred in subjects aged 30-39 years (Figure 2). Disease-free third molars occurred more often in the maxilla than in the mandible, except in the age group 40-49 years, where the mandible prevailed $\left(\chi^{2}=24.284 ; \mathrm{df}=4 ; \mathrm{P}<0.001\right)$. Disease-free third molars were found equally often in men and women $\left(\chi^{2}=7.001 ; \mathrm{df}=4 ; \mathrm{P}=0.136\right)$.

A detailed age distribution for occlusal, cervical, and apical levels of disease-free third molars is presented in Figure 3. Difference between the percentages of disease-free third molars at cervical level was $42 \%$ between the ages from 30 to 50 years.

Comparison of the characteristics of third molars according to disease status revealed that a disease-free third molar in the maxilla occurred either erupted or in bone $\left(\chi^{2}=493,68 ; \mathrm{df}=2 ; \mathrm{P}<0.001\right)$, in vertical position $\left(\chi^{2}=129,55 ; \mathrm{df}=4 ; \mathrm{P}<0.001\right)$, or at occlusal or apical level with the neighboring second molar $\left(\chi^{2}=466,22 ; \mathrm{df}=2 ; \mathrm{P}<0.001 ;\right.$ Table 3$)$. A disease-free third molar in the mandible occurred most probably in bone $\left(\chi^{2}=595,37 ; \mathrm{df}=2 ; \mathrm{P}<0.001\right)$, in inclined position $\left(\chi^{2}=165,47 ; \mathrm{df}=4 ; \mathrm{P}<0.001\right)$, at cervical or apical level with the neighboring second molar $\left(\chi^{2}=600,25 ; \mathrm{df}=2 ; \mathrm{P}<0.001\right)$, or in close contact with the mandibular canal $\left(\chi^{2}=327.64 ; \mathrm{df}=3 ; \mathrm{P}<0.001\right.$; Table 3$)$.

In both jaws together, a third molar with a deeper location than occlusal level with the neighboring second molar was more likely to be disease-free than a tooth at occlusal level, both for those at cervical level (OR=6.0; 95\% CI 4.94-7.37) and at apical level (OR=10.1; 95\% CI 8.52-12.05; Table 4). In the maxilla, the odds of being disease-free were 8.5 (95\% CI 6.65-10.92) times greater for a tooth at apical level with the neighboring second molar than for a tooth at occlusal or cervical level. In the mandible, a tooth at cervical or apical level with the neighboring second molar was 6.2 (95\% CI 4.98-7.82) times more probably disease-free than a tooth at occlusal level. A mandibular tooth in a close relationship with the mandibular canal was 1.6 (95\% CI 1.29-1.98) times more likely to be disease-free than a tooth apart from the canal. Angulation of the third molar was not an important characteristic in any of the three models. In the binomial logistic regression analysis, we found an excellent fit for all three models. Figure 4 illustrates the main findings of the models. 


\section{Discussion}

The main result of this study was that a deeply situated third molar - either at cervical or especially apical level with the neighboring second molar - clearly more likely remained disease-free than a tooth at occlusal level. This finding is surprising because for decades the literature has concluded that impaction is a disease and a potential risk that necessitates the extraction of the tooth [10, 13-16]. This discrepancy between the present and earlier studies is explained by the earlier studies using smaller and selected patient samples of young adults, mostly from surgical practices, and focusing on impacted third molars alone. However, our sample represented the entire population aged 30 years and over and included all third molars.

This study is the first attempt in the literature to identify and characterize disease-free third molars in an entire adult population aged 30-93 years. This information is important for the clinician when assessing the possibilities of a third molar to remain disease-free if left in situ. Large case series with panoramic radiographs and representing a whole population do not exist for comparison of the significance of our results.

It is difficult to explain our finding of third molars at cervical level, i.e. those partially erupted, that remained disease-free in our population aged 30 years and over. It is well known that partially erupted third molars are especially prone to sustaining pericoronitis, which is one of the most common indications for extraction. It is also established that related to mandibular third molars in patients aged 15-80 years and referred for removal, pericoronitis is the most common pathosis (64\%), with subjects younger than 30 years representing $66 \%$ of all pathoses [17]. An earlier study also reported that the peak age of pericoronitis varies between 21 and 25 years, and only a few episodes occur later in life [18]. In another follow-up study, older age groups were found to be less likely than younger age groups to develop symptoms in their initially asymptomatic impacted third molars [19]. However, from our Figure 3 it is evident that the difference between the proportions of disease-free third molars at cervical level was dramatic (42\%) between the ages from 30 to 50 years. Therefore, our results suggest that third molars at cervical level do not easily remain disease-free in adult population.

From the demographic features of our subjects, it was not surprising that age, gender, and level of education reached statistical significance for disease-free status of third molars. Younger age, female 
gender, and higher education are generally well-recognized features associated with good oral health [2]. In the US study of disease-free third molars, young age and high level of education were also mentioned in addition to good oral health habits [4]. In our study, the place of residence was not significantly associated with disease-free status, indicating that oral health care services are evenly distributed and available to the whole population in Finland.

Our definition for a disease-free tooth was not exactly the same as previously presented [20]. The main difference was that we did not inquire about symptoms in our subjects. A disease-free third molar has previously been characterized as having no symptoms, hygienic, functional, no clinical or radiographic findings of signs of disease, attached gingiva around the erupted tooth, and if the tooth is not visible then it cannot be probed from the distal pocket of the second molar [20]. According to these definitions, 37.3\% of third molars in patients at oral and maxillofacial surgical practice are asymptomatic and also diseasefree [5]. In our material, the prevalence of disease-free third molars in the youngest age group of 30-39 years was $52 \%$, but in all subjects it was $29 \%$.

From our independent variables in the regression analysis, the depth in the bone showed a better fit than the type of impaction. It is also easier to record it from the panoramic radiograph compared with the assessment of impaction, i.e. how much is two-thirds of a tooth above bone or in bone, as is the definition for the type of impaction.

Our results on depth in the bone agree with the relationship with the mandibular canal. Disease-free status was related to deep location in the bone and also to a close relation with the mandibular canal. If we revert to the introduction of this study, a third molar in a deep position close to the mandibular canal may be left in situ because the probability of the tooth remaining disease-free was 1.6 to 6.2 times higher than a tooth in a more superficial position. An earlier study also confirms the anatomical relationship, namely that erupted third molars are located farther from the canal than unerupted and inclined third molars [21].

Although our main finding was surprising, it is important to note that our study protocol was crosssectional. However, the statistical analyses with binomial regression analysis were crucial to find relevant characteristics of third molars for disease-free status. In the bivariate analysis of Table 3, the characteristics for disease-free status were slightly contradictory to results from regression analysis. For instance, angulation of the third molar was significant in bivariate analysis, but it was not an important 
characteristic according to the regression analysis. It is also noteworthy that our results represent the population aged 30 years and above. It may be that subjects younger than this possess disease-free third molars that are different from those described here. As an example, a newly erupted third molar at occlusal level in a 20-year-old subject may initially be disease-free.

It is well documented that a third molar may cause caries and periodontal problems to the neighboring second molar. In adult men population, a second molar adjacent to a soft tissue impacted third molar is at highest risk for developing distal bone loss or distal probing depths more than $4 \mathrm{~mm}$ [10]. Contrary to that result, in our previous study on the same adult population as the present study, it is shown that a deepened pocket was found most often adjacent to an erupted third molar [6]. In the present study, when identifying disease-free third molars, the pocket depths were clinically examined from the neighboring second molars, and only if the pockets were less than $4 \mathrm{~mm}$, then the third molar was defined as disease-free in this study. Horizontal and vertical bone loss around the third molar was also assessed. However, our deeply situated and disease-free third molar may cause dental diseases to the second molar later in life, because a little more than a half of our disease-free third molars occurred in the age group of 30-39 years.

In conclusion, our results provide important data on the natural history of third molars in adults. Onefourth of third molars may remain disease-free after the age of 30 years, particularly in younger females with a high level of education. The most interesting characteristic of disease-free third molars was the depth in the bone; a third molar situated deeper in the bone was more likely to be disease-free than a tooth at occlusal level.

\section{Compliance with Ethical Standards}

Conflict of interests: The authors declare that they have no conflict of interest.

Funding: Field surveys were organized by the National Institute for Health and Welfare (THL) in Finland and partly funded by the Finnish Dental Society Apollonia and the Finnish Dental Association. Planmeca Oy placed digital panoramic X-ray apparatus and software at our disposal during the survey. The first author received a grant for this study from the Finnish Association of Women Dentists. 
Ethical approval: All procedures performed in studies involving human participants were in accordance with the ethical standards of the institutional and/or national research committee and with the 1964 Helsinki declaration and its later amendments or comparable ethical standards.

Informed consent: Informed consent was obtained from all individual participants included in the study.

\section{References}

1. Bouloux GF, Busaidy KF, Beirne OR, Chuang S-K, Dodson TB (2015) What is the risk of future extraction of asymptomatic third molars? A systematic review. J Oral Maxillofac Surg 73:806-811

2. Suominen-Taipale L, Nordblad A, Vehkalahti M, Aromaa A (eds) (2008) Oral health in the Finnish adult population. Health 2000 Survey. Publications of the National Public Health Institute B25/2008, Helsinki Finland 2008. http://www.julkari.fi/handle/10024/103030. Accessed 28 May 2018

3. Magraw CBL, Moss KL, Fisher EL, Offenbacher S, White RP Jr (2016) Prevalence of visible third molars in the United States population: How many individuals have third molars? J Oral Maxillofac Surg 74:13-17

4. Golden BA, Baldwin C, Sherwood C, Abdelbaky O, Phillips C, Offenbacher S, White RP Jr (2015) Monitoring for periodontal inflammatory disease in the third molar region. J Oral Maxillofac Surg 73:595-599

5. Kinard BE, Dodson TB (2010) Most patients with asymptomatic, disease-free third molar elect extraction over retention as their preferred treatment. J Oral Maxillofac Surg 68:2935-2942

6. Ventä I, Vehkalahti MM, Huumonen S, Suominen AL (2017) Signs of disease occur in the majority of third molars in an adult population. Int J Oral Maxillofac Surg 46:1635-1640

7. National Institute for Health and Welfare (2017) Population studies. Health 2000-2011 Surveys. National Institute for Health and Welfare, Finland 2017. https://thl.fi/en/web/thlfi-en/research-andexpertwork/population-studies. Accessed 28 May 2018

8. Aromaa A, Koskinen S (eds) (2004) Health and functional capacity in Finland. Baseline results of the Health 2000 Health examination survey. Publications of the National Public Health Institute B12/2004. Helsinki, Finland 2004. http://www.julkari.fi/bitstream/handle/10024/78534/KTLB122004.pdf?sequence=1. Accessed 28 May 2018 
9. Heistaro S (2008) Methodology report. Health 2000 Survey. Publications of the National Public Health Institute B 26/2008. National Public Health Institute. Helsinki, Finland 2008. http://www.julkari.fi/bitstream/handle/10024/78185/2008b26.pdf?sequence=1. Accessed 28 May 2018

10. Nunn ME, Fish MD, Garcia RI, Kaye EK, Figueroa R, Gohel A, Ito M, Lee HJ, Williams DE, Miyamoto T (2013) Retained asymptomatic third molars and risk for second molar pathology. J Dent Res 92:1095-1099

11. Pell G, Gregory B (1933) Impacted mandibular third molars: Classification and modified techniques for removal. Dent Digest 39:330-338

12. Ventä I, Murtomaa H, Turtola L, Meurman J, Ylipaavalniemi P (1991) Assessing the eruption of lower third molars on the basis of radiographic features. Br J Oral Maxillofac Surg 29:259-262

13. National Institutes of Health (NIH) (1980) NIH consensus development conference for removal of third molars. J Oral Surg 38:235-236

14. Stanley HR, Alattar M, Collett WK, Stringfellow HR JR, SpiegeL EH (1988) Pathological sequelae of "neglected" impacted third molars. J Oral Pathol 17:113-117

15. Eliasson S, Heimdahl A, Nordenram Å (1989) Pathological changes related to long-term impaction of third molars. A radiographic study. Int J Oral Maxillofac Surg 18:210-212

16. Huang H, Mercier P (1992) Asymptomatic impacted teeth in edentulous jaws undergoing preprosthetic surgery. A long term evaluation. Int J Oral Maxillofac Surg 21:147-149

17. Knutsson K, Brehmer B, Lysell L, Rohlin M (1996) Pathoses associated to third molars subjected to removal. Oral Surg Oral Med Oral Pathol Oral Radiol Endod 82:10-17

18. Kay LW (1966) Investigations into the nature of pericoronitis. Br J Oral Surg 3:188-205

19. Fernandes MJ, Ogden GR, Pitts NB, Ogston SA, Ruta DA (2010) Actuarial life-table analysis of lower impacted wisdom teeth in general dental practice. Community Dent Oral Epidemiol 38:58-67

20. Dodson TB (2012) How many patients have third molars and how many have one or more asymptomatic, disease-free third molars? J Oral Maxillofac Surg 70(Suppl 1):4-7

21. Miloro M, Dabell J (2005) Radiographic proximity of the mandibular third molar to the inferior alveolar canal. Oral Surg Oral Med Oral Pathol Oral Radiol Endod 100:545-549 
Table 1. Measurements of characteristics of third molars in panoramic radiographs.

\begin{tabular}{|c|c|c|}
\hline Characteristic & Category & Definition \\
\hline \multirow[t]{3}{*}{ State of impaction } & Erupted & $\begin{array}{l}\text { Cemento-enamel junction mesially and } \\
\text { distally above the bone }\end{array}$ \\
\hline & $\begin{array}{l}\text { Impacted in soft } \\
\text { tissue }\end{array}$ & $\begin{array}{l}\text { Less than two-thirds of the crown inside the } \\
\text { bone }\end{array}$ \\
\hline & Impacted in bone & $\begin{array}{l}\text { Two-thirds or more of the crown inside the } \\
\text { bone }\end{array}$ \\
\hline \multirow[t]{5}{*}{ Angulation } & Vertical & 0-10 degrees \\
\hline & Mesioangular* & 11-70 degrees \\
\hline & Distoangular* & $<0$ degrees \\
\hline & Mesiohorizontal* & $>71$ degrees \\
\hline & Other* & Inverted or transversal \\
\hline \multirow[t]{3}{*}{ Depth in the bone } & Occlusal & $\begin{array}{l}\text { Highest point of third molar was level with } \\
\text { or higher than the occlusal surface of the } \\
\text { neighboring second molar }\end{array}$ \\
\hline & Cervical & $\begin{array}{l}\text { Between the levels of the occlusal surface } \\
\text { and the cemento-enamel junction of the } \\
\text { neighboring second molar }\end{array}$ \\
\hline & Apical & $\begin{array}{l}\text { On cemento-enamel junction of the } \\
\text { neighboring second molar or below this } \\
\text { point }\end{array}$ \\
\hline Relationship with & Apart & Apart from the canal \\
\hline \multirow[t]{3}{*}{ mandibular canal } & Tangential & Tangential to the canal \\
\hline & Superimposed & Superimposed with the canal \\
\hline & Inferior & Inferior to the canal \\
\hline
\end{tabular}

*Mesioangular, distoangular, mesiohorizontal, and other=inclined. 
Table 2. Characteristics (\%) of subjects ( $n=2653$ ) with one or more third molars according to disease status.

\begin{tabular}{|c|c|c|c|c|c|}
\hline Characteristic & $\begin{array}{l}\text { Only disease- } \\
\text { free third } \\
\text { molars }\end{array}$ & $\begin{array}{l}\text { Both disease- } \\
\text { free and } \\
\text { diseased third } \\
\text { molar }\end{array}$ & $\begin{array}{l}\text { Only diseased } \\
\text { third molars }\end{array}$ & Total & P-value \\
\hline \multicolumn{6}{|l|}{ Age } \\
\hline $\begin{array}{l}\text { Mean [SD] } \\
\text { years }\end{array}$ & $43.5[11.5]$ & $43.1[10.0]$ & 49.4 [11.7] & 2653 & $0.001^{\S}$ \\
\hline Gender & & & & 2653 & $0.001 *$ \\
\hline Male & $198(46)$ & $359(63)$ & $911(55)$ & 1468 & \\
\hline Female & $236(54)$ & $208(37)$ & $741(45)$ & 1185 & \\
\hline Education\# & & & & 2638 & $0.001 *$ \\
\hline Basic & $94(22)$ & $120(21)$ & $492(30)$ & 706 & \\
\hline Medium & $159(37)$ & $218(39)$ & $616(38)$ & 993 & \\
\hline High & $180(41)$ & $225(40)$ & $534(32)$ & 939 & \\
\hline $\begin{array}{l}\text { Place of } \\
\text { residence }\end{array}$ & & & & 2653 & $0.552 *$ \\
\hline City & $272(63)$ & $348(62)$ & $1074(65)$ & 1694 & \\
\hline Town & $60(14)$ & $87(15)$ & $222(13)$ & 369 & \\
\hline Countryside & $102(23)$ & $132(23)$ & $356(22)$ & 590 & \\
\hline Total & $434(16)$ & $567(22)$ & $1652(62)$ & 2653 & \\
\hline
\end{tabular}

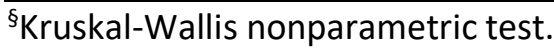

${ }^{*} \chi^{2}$ test.

\# Level of education was not available for 15 subjects. 
Table 3. Characteristics of third molars $(n=5665)$ in upper and lower jaws according to disease status.

\begin{tabular}{|c|c|c|c|c|c|c|}
\hline & Maxilla & & & Mandible & & \\
\hline Characteristic & $\begin{array}{l}\text { Disease- } \\
\text { free } \\
n(\%)\end{array}$ & $\begin{array}{l}\text { Diseased } \\
\mathrm{n}(\%)\end{array}$ & $\begin{array}{l}\text { P- } \\
\text { value* }\end{array}$ & $\begin{array}{l}\text { Disease- } \\
\text { free } \\
n(\%)\end{array}$ & $\begin{array}{l}\text { Diseased } \\
\mathrm{n}(\%)\end{array}$ & $\begin{array}{l}\text { P- } \\
\text { value* }\end{array}$ \\
\hline Impaction & & & 0.001 & & & 0.001 \\
\hline Erupted & $388(48)$ & 1440 (89) & & $237(27)$ & $1494(63)$ & \\
\hline Soft tissue & $40(5)$ & $38(2)$ & & $195(23)$ & $618(26)$ & \\
\hline In bone & $383(47)$ & $147(9)$ & & $426(50)$ & $259(11)$ & \\
\hline Angulation & & & $0.001 * *$ & & & $0.001^{* *}$ \\
\hline Vertical & $491(61)$ & $1262(78)$ & & 316 (37) & $1287(54)$ & \\
\hline Mesioangular & $184(23)$ & $294(18)$ & & 247 (29) & $741(31)$ & \\
\hline Distoangular & $118(14)$ & $58(3)$ & & $183(21)$ & $252(11)$ & \\
\hline Mesiohorizontal & $11(1)$ & $1(0)$ & & $107(12)$ & $87(4)$ & \\
\hline Other & $7(1)$ & $10(1)$ & & $5(1)$ & $4(0)$ & \\
\hline Depth in bone & & & 0.001 & & & 0.001 \\
\hline Occlusal & $383(47)$ & $1410(87)$ & & $378(44)$ & $2045(86)$ & \\
\hline Cervical & $70(9)$ & $77(5)$ & & $226(26)$ & $166(7)$ & \\
\hline Apical & $358(44)$ & $138(8)$ & & $254(30)$ & $160(7)$ & \\
\hline Canal relation & - & - & & & & 0.001 \\
\hline Apart & & & & $327(38)$ & 1624 (69) & \\
\hline Tangential\# & & & & $144(17)$ & $353(15)$ & \\
\hline Superimposed\# & & & & $289(34)$ & $337(14)$ & \\
\hline Inferior\# & & & & $98(11)$ & $57(2)$ & \\
\hline Total & $811(33)$ & 1625 (67) & & $858(27)$ & $2371(73)$ & \\
\hline
\end{tabular}


Table 4. Role of characteristics of maxillary $(n=2436)$ and mandibular $(n=3229)$ third molars related to the likelihood that a third molar is disease-free, by means of logistic regression modeling. Reference group is in square brackets.

\begin{tabular}{|c|c|c|c|c|c|c|}
\hline Jaw & Characteristic & Coefficient & SE & OR & $95 \% \mathrm{Cl}$ & P-value \\
\hline \multicolumn{7}{|c|}{ Maxilla and mandible } \\
\hline & \multicolumn{6}{|c|}{ Depth in bone [Occlusal] } \\
\hline & Cervical & 1.798 & 0.102 & 6.0 & $4.94 ; 7.37$ & 0.001 \\
\hline & Apical & 2.316 & 0.089 & 10.1 & $8.52 ; 12.05$ & 0.001 \\
\hline & \multicolumn{6}{|c|}{ Angulation [Vertical] } \\
\hline & Inclined* & -0.181 & 0.074 & 0.8 & $0.72 ; 0.96$ & 0.014 \\
\hline & Constant & -1.462 & 0.045 & & & \\
\hline & \multicolumn{4}{|c|}{ Hosmer and Lemeshow test } & & 0.738 \\
\hline \multicolumn{7}{|c|}{ Maxilla } \\
\hline & \multicolumn{6}{|c|}{ Angulation [Vertical] } \\
\hline & Inclined* & -0.002 & 0.116 & 1.0 & $0.80 ; 1.25$ & 0.988 \\
\hline & \multicolumn{6}{|c|}{ Depth in bone [Occlusal and cervical] } \\
\hline & Apical & 2.143 & 0.127 & 8.5 & $6.65 ; 10.92$ & 0.001 \\
\hline & Constant & -1.188 & 0.058 & & & \\
\hline & Hosmer and Lemes & w test & & & & 0.923 \\
\hline \multicolumn{7}{|c|}{ Mandible } \\
\hline & \multicolumn{6}{|c|}{ Angulation [Vertical] } \\
\hline & Inclined* & 0.012 & 0.098 & 1.0 & $0.84 ; 1.23$ & 0.906 \\
\hline & \multicolumn{6}{|c|}{ Canal relation [Apart] } \\
\hline & Close relation** & 0.467 & 0.110 & 1.6 & $1.29 ; 1.98$ & 0.001 \\
\hline & \multicolumn{6}{|c|}{ Depth in bone [Occlusal] } \\
\hline & Cervical and apical & 1.832 & 0.115 & 6.2 & $4.98 ; 7.82$ & 0.001 \\
\hline & Constant & -1.751 & 0.071 & & & \\
\hline & \multicolumn{5}{|c|}{ Hosmer and Lemeshow test } & 0.926 \\
\hline
\end{tabular}

$\mathrm{SE}=$ standard error; OR=odds ratio; $\mathrm{Cl}=$ confidence interval; *Inclined=mesioangular, distoangular, mesiohorizontal, and other inclinations; ${ }^{* *}$ Close relation=tangential, superimposed, and inferior relationships. 


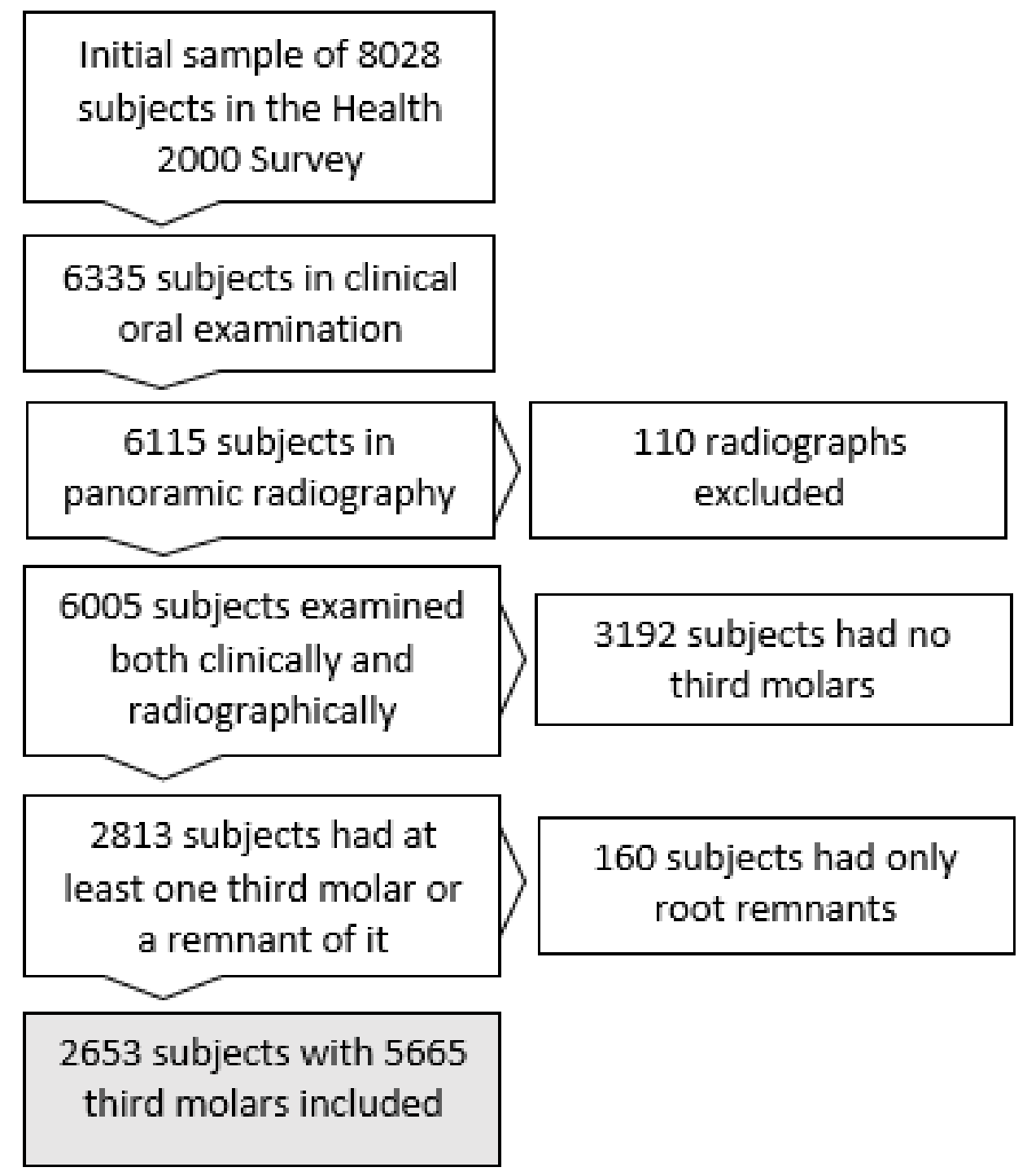

Fig. 1 Flow diagram of the number of subjects and third molars in the study 


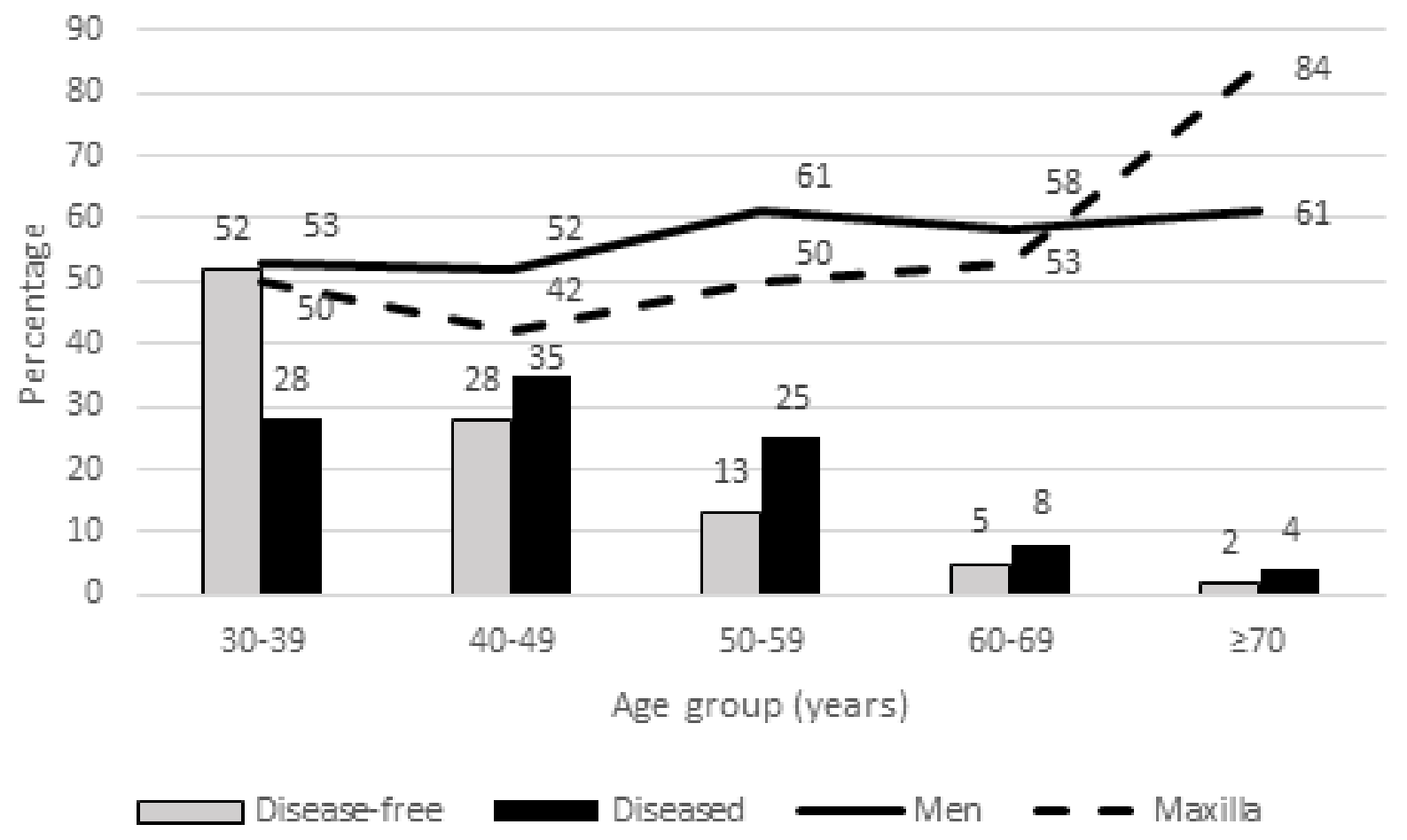

Fig. 2 Distribution (\%) of the 5665 third molars according to disease status, age, gender, and jaw. The solid line indicates the proportions of disease-free third molars in men, and the dashed line indicates the proportions of disease-free third molars in the maxilla 


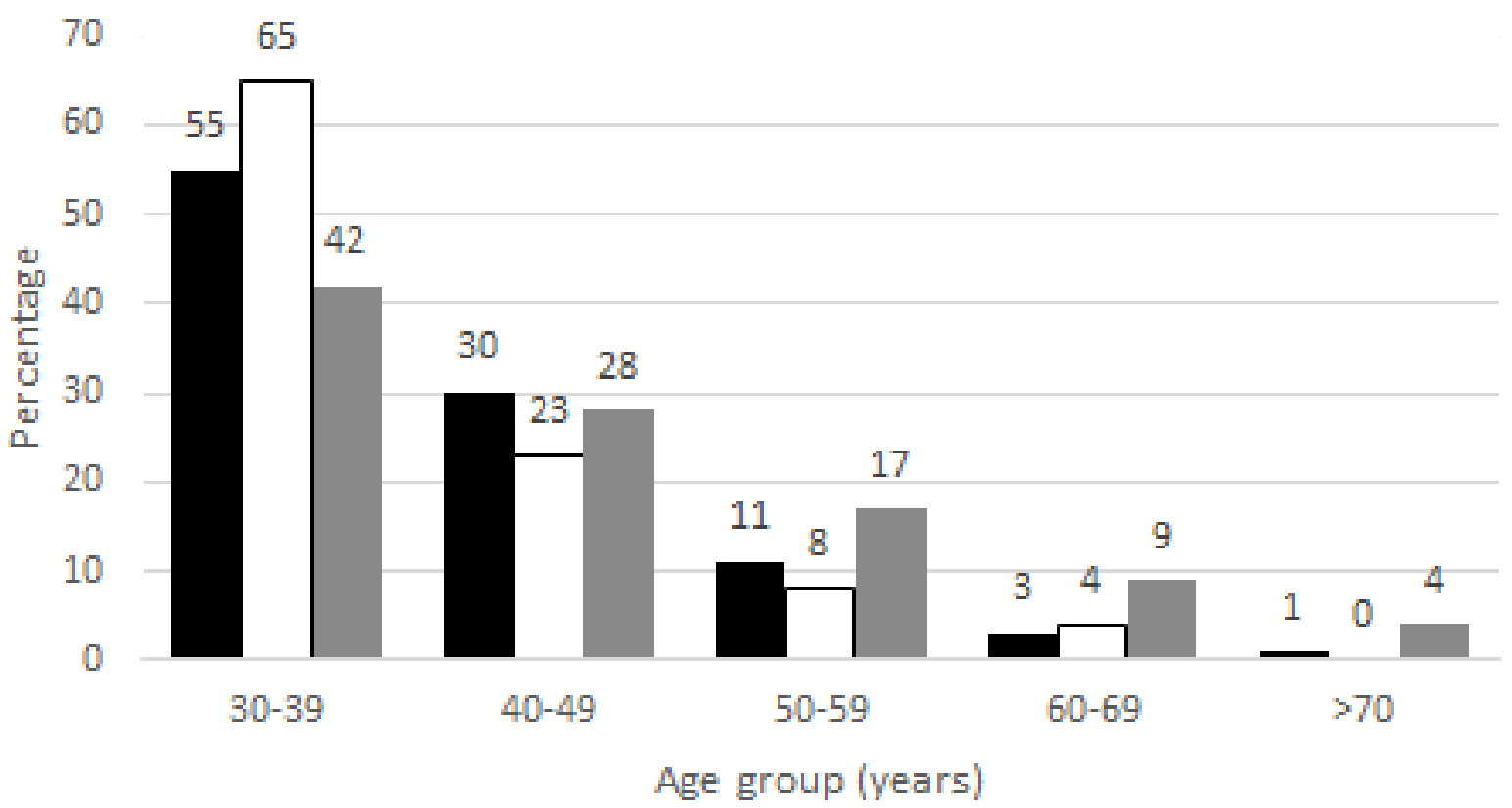

- Occlusal aCervical apical

Fig. 3 Distribution (\%) of the 1669 disease-free third molars according to occlusal, cervical, and apical levels, by age group 


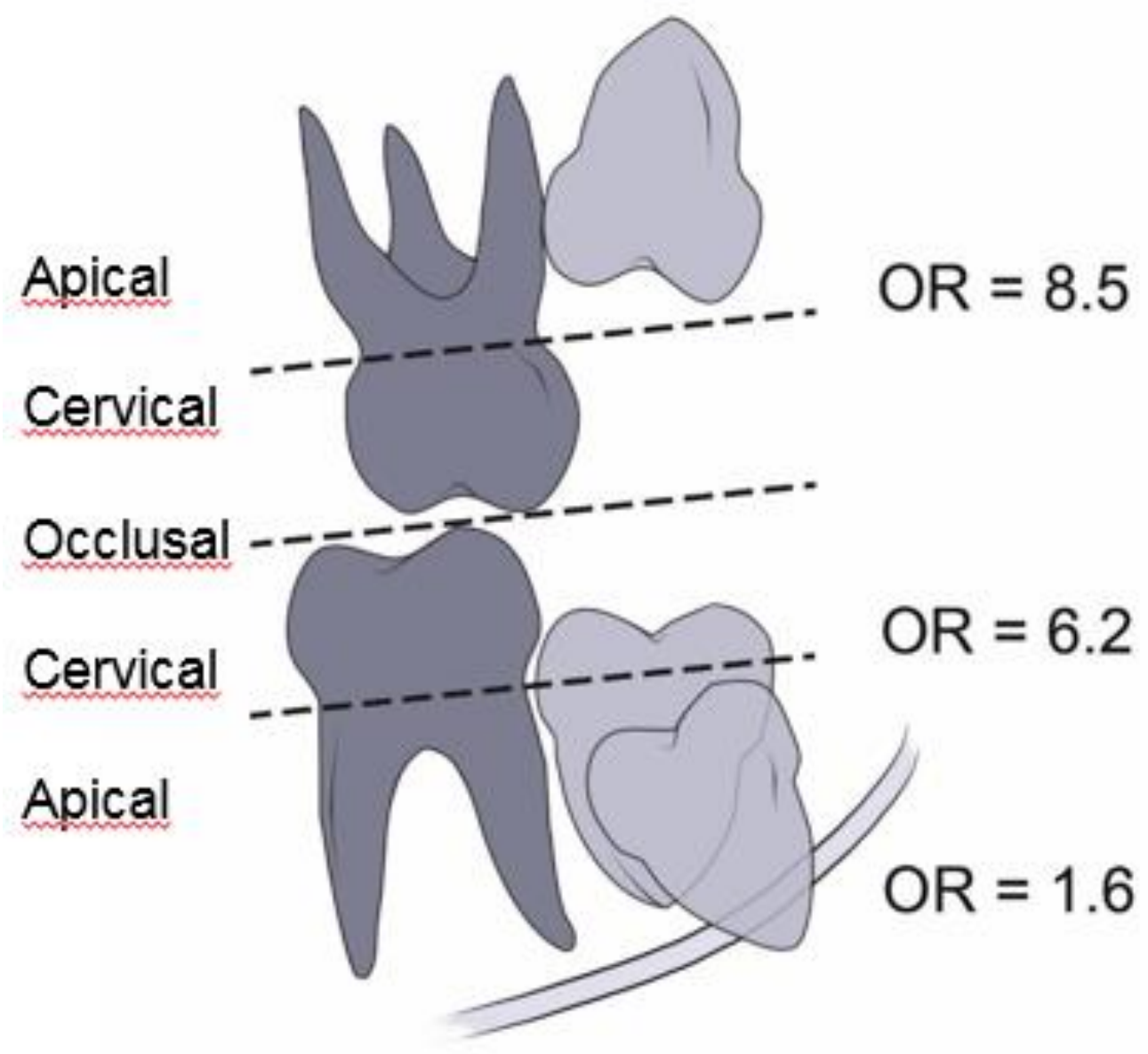

Fig. 4 In the maxilla, a third molar above the cervical line was 8.5 times more likely to be disease-free than a tooth in a more superficial position. In the mandible, a third molar above or below the cervical line of the neighboring second molar was 6.2 times more likely to be disease-free than a tooth at occlusal level. A tooth in close relation to mandibular canal was 1.6 times more likely to be disease-free than a tooth not in contact with the canal. (OR=odds ratio) 